\title{
Day case surgery: geographical variation, trends and readmission rates
}

\author{
J HENDERSON, M J GOLDACRE, M GRIFFITH, AND H M SIMMONS \\ From the Unit of Clinical Epidemiology, University of Oxford, Oxford Regional Health Authority, Headington, \\ Oxford.
}

\begin{abstract}
Data from the Oxford Record Linkage Study were analysed to determine the amount of work undertaken in day case surgery for 12 surgical conditions in five districts in the Oxford Region during the years 1976 to 1985 . Record linkage was used to study readmission rates, comparing day surgery with inpatient care. The use of day surgery gradually increased in some conditions (eg, termination of pregnancy, female sterilisation) but did not increase from a fairly low base for others (eg, inguinal hernia repair, operations on varicose veins and haemorrhoids). There were striking differences between the districts in the use of day case care. For example, the use of day case care as a percentage of all hospital admissions for termination of pregnancy varied from $1 \%$ in one district to $24 \%$ in another; that for dilatation and curettage varied from $1 \%$ to $43 \%$; and that for female sterilisation varied from $<1 \%$ to $35 \%$. Emergency readmission rates after day surgery were similar to those following inpatient treatment. We conclude that the use of day surgery for some conditions judged suitable for day care is still low and, even within one region, variation in the use of day surgery is considerable. The reasons for continued reluctance in some places to undertake more day surgery merit investigation.
\end{abstract}

Treatment of patients with certain conditions by day case surgery has been advocated for many years. ${ }^{1-7}$ Day surgery is considered to have several advantages over inpatient treatment, including lower costs per case, an effect of reducing surgical waiting lists and waiting times, lower risks of cross infection and thrombotic complication and often greater convenience for the patient. ${ }^{67}$ Day surgery is thought to be particularly advantageous for children because it involves less time away from home.

Interest in day surgery has increased in recent years. The Royal College of Surgeons has recommended a wide range of surgical procedures as being suitable for day care providing that due consideration is given to patients' age, general health and social circumstances. ${ }^{6}$ Some Regions have set targets for day care in their strategic plans: for example, in the Oxford Region it is proposed that 25 per cent of hospital admissions in the acute services could be undertaken on a day care basis by $1994 .^{8}$ Comparisons between districts in their use of day care have also been included in the national Performance Indicators package. ${ }^{9}$

Data on day cases have been collected in five of the six districts covered by the Oxford Record Linkage
Study since 1976. In this paper we report on trends over time, variation between the districts, and readmission rates for day surgery in these districts for selected conditions.

\section{Methods}

The five districts, which have a current population of about 1.8 million people, are situated in southern England and are served by the full range of medical and surgical services. A day case was defined as a person who was admitted to hospital as an elective admission, who was discharged home on the same day, and who underwent operation. Such cases were included whether or not they were treated in purpose built day care facilities. Inpatients were patients who were elective admissions and who underwent the same range of operations but who stayed in hospital for at least one night. Twelve conditions considered suitable for day surgery by various authors were selected for inclusion in the analysis reported here (see table 1).

For the purpose of this study readmissions were defined as subsequent admissions (other than transfers) which occurred (1) within $28 \mathrm{~d}$ and (2) within $365 \mathrm{~d}$ of discharge from the initial episode 
Table 1 Conditions and operations included in the study

\begin{tabular}{|c|c|c|c|}
\hline \multirow[b]{2}{*}{ Condition } & \multicolumn{2}{|c|}{ Diagnostic codes } & \multirow{2}{*}{$\frac{\text { Operation codes }}{\text { OPCS }}$} \\
\hline & $I C D 8^{*}$ & $(I C D 9) \dagger$ & \\
\hline Inguinal hernia with repair & 550 & & 411 \\
\hline Haemorrhoids & 455 & & $490-495$ \\
\hline Varicose veins & 454 & & $890-898$ \\
\hline Myringotomy & 381 & & 193 \\
\hline Termination of pregnancy & - & & 742 \\
\hline Dilatation and curettage & - & & 703,704 \\
\hline Female sterilisation & Y43 & V25 & 684,687 \\
\hline Vasectomy & Y43 & V25 & 651 \\
\hline Hydrocele & 603 & & 644 \\
\hline Circumcision & 605 & & 661 \\
\hline Cataract & 374 & 366 & $\begin{array}{l}170,172-4,176 \\
178-179\end{array}$ \\
\hline Strabismus & 373 & 378 & $110,112-115$ \\
\hline
\end{tabular}

* ICD8-8th revision of the International Classification of Diseases † ICD9-9th revision (given where different from ICD8)

$\ddagger$ OPCS - Office of Population Censuses and Surveys, Operation Code (3rd revision)

of hospital care. Emergency readmissions were distinguished from those designated as planned readmissions (ie, admissions from the waiting list, booked admissions and booked readmissions). Analyses of trends and geographical differences in the use of day surgery were based upon all patients treated in the five districts. The analysis of readmissions was based upon patients treated in the five districts but excluded patients resident elsewhere because, we reasoned, if readmission was required, it may have been to a hospital outside the five districts. We also calculated readmission rates in the total treated population, which were similar to those described here. Readmission rates were standardised for differences in the age structure of the day case and inpatient populations for each condition. The indirect method of standardisation was used and the sum of the day cases and inpatients for each condition was taken as the standard population. Differences between readmission rates comparing inpatients and day cases were tested for statistical significance by $\chi^{2}$.

Where there were several possible operations for a condition, eg, cataract or haemorrhoids, the trend in the use of day case care for each operation was analysed, both separately for each operation (as classified at the three digit level of the Office of Population Censuses and Surveys operation codes) and for the operations as a group.

Completeness of recording of inpatients and day cases on the Oxford Record Linkage Study files was checked by comparing the counts of these records with the $\mathrm{SH} 3$ returns (routine aggregate counts of numbers of inpatients and day cases discharged from each specialty in each hospital) for the relevant years, districts and specialties. No important discrepancies between these two independent sources of data were found in numbers of cases reported for each relevant specialty in each district.

\section{Results}

The percentage of patients managed as day cases increased over the years for several conditions (table 2). The table also shows the average annual number of patients treated for each condition and the range of numbers in each year. (The latter show the numbers treated in the years with the least and the most patients which, of course, are not necessarily the earliest and latest years in the study period.) Large increases in day case work were recorded for termination of pregnancy which increased from 5 per cent to 47.6 per cent over the 10 years, and for female sterilisation which increased from 1.9 per cent to 30.4 per cent. The percentage of myringotomies treated in day surgery increased fourfold from 8.7 per cent in 1976 to 36.4 per cent in 1985. Cataract and strabismus were only treated as day cases in one district in which there was a considerable increase in the use of day surgery between 1976 and 1985.

There was evidence of a decline in day surgery for haemorrhoids and varicose veins; and day surgery for inguinal hernia was low throughout the period at around 6 per cent of all such operations (see table 2).

Considerable differences between districts in the use of day case care were found (table 3). District 1 and District 5 generally undertook the highest percentages? of work in day surgery; and District 3 undertook the least at less than 6 per cent of all cases for 10 of the 12 conditions studied. Examples of differences between the districts in the use of day surgery include those for patients who underwent myringotomy, ranging from 0.5 to 50.1 per cent, and for those who underwent dilatation and curettage, ranging from 1.2 to 42.7 per cent.

Table 4 compares emergency readmission rates between patients who underwent day surgery and inpatient surgery. The only significant differences for emergency readmissions were those among patients who underwent female sterilisation, dilatation and curettage or cataract operations in whom more inpatients than day cases had emergency readmissions.

\section{Discussion}

An increase in the use of day case care has been advocated by individual clinicians, by the Royal College of Surgeons and by health authorities. Encouragement for the use of day care is also implicit in the Department of Health's use of Performance 
Table 2 Percentage of all cases treated as day cases in each group of conditions in each year; average number of cases each year (n) (inpatients plus day cases); and range of numbers of cases (inpatients plus day cases) in each year over the 10 years

\begin{tabular}{|c|c|c|c|c|c|c|c|c|c|c|c|c|}
\hline \multirow[b]{2}{*}{ Condition } & \multirow[b]{2}{*}{$n$} & \multirow{2}{*}{ Range } & \multicolumn{10}{|c|}{ Percentage of cases treated as day cases in each year } \\
\hline & & & 76 & 77 & 78 & 79 & 80 & 81 & 82 & 83 & 84 & 85 \\
\hline Inguinal hernia & 2582 & $2376-2793$ & 6 & 7 & 6 & 7 & 6 & 6 & 6 & 5 & 5 & 5 \\
\hline Haemorrhoids & 534 & $418-656$ & 14 & 12 & 13 & 12 & 10 & 8 & 8 & 7 & 10 & 9 \\
\hline Varicose veins & 1298 & $846-1639$ & 7 & 10 & 9 & 12 & 12 & 11 & 9 & 6 & 6 & 4 \\
\hline Termination of pregnancy & 2050 & $1854-2477$ & 5 & 3 & 2 & 4 & 5 & 8 & 13 & 25 & 42 & 48 \\
\hline Dilatation and curettage & 5478 & $4798-5800$ & 16 & 17 & 21 & 19 & 21 & 20 & 22 & 24 & 27 & 26 \\
\hline Female sterilisation & 1585 & $1029-2406$ & 2 & 2 & 8 & 13 & 11 & 11 & 8 & 13 & 18 & 30 \\
\hline Vasectomy & 1133 & $958-1451$ & 94 & 91 & 91 & 93 & 93 & 94 & 92 & 93 & 91 & 92 \\
\hline Hydrocele & 236 & $201-266$ & 13 & 7 & 10 & 9 & 8 & 16 & 11 & 12 & 16 & 17 \\
\hline Circumcision & 866 & $832-927$ & 25 & 28 & 29 & 30 & 30 & 28 & 24 & 25 & 32 & 37 \\
\hline Cataract & 1260 & $814-1585$ & 1 & 6 & 9 & 10 & 14 & 15 & 17 & 19 & 15 & 19 \\
\hline Strabismus & 631 & $531-860$ & 6 & 9 & 10 & 10 & 9 & 7 & 8 & 7 & 7 & 8 \\
\hline
\end{tabular}

Table 3 Percentage of all cases treated as day cases in each district 1976-85 with 1985 in parentheses; average total number of cases treated in each district $(n)$ and range of district totals

\begin{tabular}{|c|c|c|c|c|c|c|c|}
\hline \multirow[b]{2}{*}{ Condition } & \multirow[b]{2}{*}{$n$} & \multirow[b]{2}{*}{ Range } & \multicolumn{5}{|l|}{ District } \\
\hline & & & 1 & 2 & 3 & 4 & 5 \\
\hline Inguinal hernia & 5165 & $3626-7738$ & $15(12)$ & $1(3)$ & $<1(0)$ & $7(4)$ & $1(4)$ \\
\hline Haemorrhoids & 1068 & $596-1673$ & $12(7)$ & $6(10)$ & $3(10)$ & $36(21)$ & $1(0)$ \\
\hline Varicose veins & 2596 & $1935-3954$ & $10(1)$ & $<1(1)$ & $1(5)$ & $29(21)$ & $4(<1)$ \\
\hline Termination of pregnancy & 4101 & $1893-9980$ & 24(79) & $11(18)$ & 1(1) & $22(34)$ & $5(15)$ \\
\hline Dilatation and curettage & 10955 & $7302-16251$ & 23(37) & $26(31)$ & 1(3) & $14(22)$ & 43(49) \\
\hline Female sterilisation & 3171 & $1911-5475$ & $7(35)$ & $14(51)$ & $<1(2)$ & $4(15)$ & $35(62)$ \\
\hline Vasectomy & 2265 & $606-4568$ & $85(86)$ & 97(98) & 72(77) & $87(87)$ & 98(99) \\
\hline Hydrocele & 472 & $258-648$ & $32(36)$ & $2(10)$ & $1(0)$ & $16(13)$ & 4(19) \\
\hline Circumcision & 1733 & $942-2637$ & $54(61)$ & $9(30)$ & $5(6)$ & $34(27)$ & $34(49)$ \\
\hline Cataract & 3149 & $2020-4220$ & $<1(<1)$ & $<1(<1)$ & $<1(0)$ & $*$ & $84(97)$ \\
\hline Strabismus & 1578 & $568-2348$ & $<1(1)$ & $<1(0)$ & $0(0)$ & $*$ & $89(93)$ \\
\hline
\end{tabular}

* No ophthalmology service in this district

Table 4 Percentage of inpatients (IP) and day cases (DC) readmitted as emergencies within 28 days and 365 days

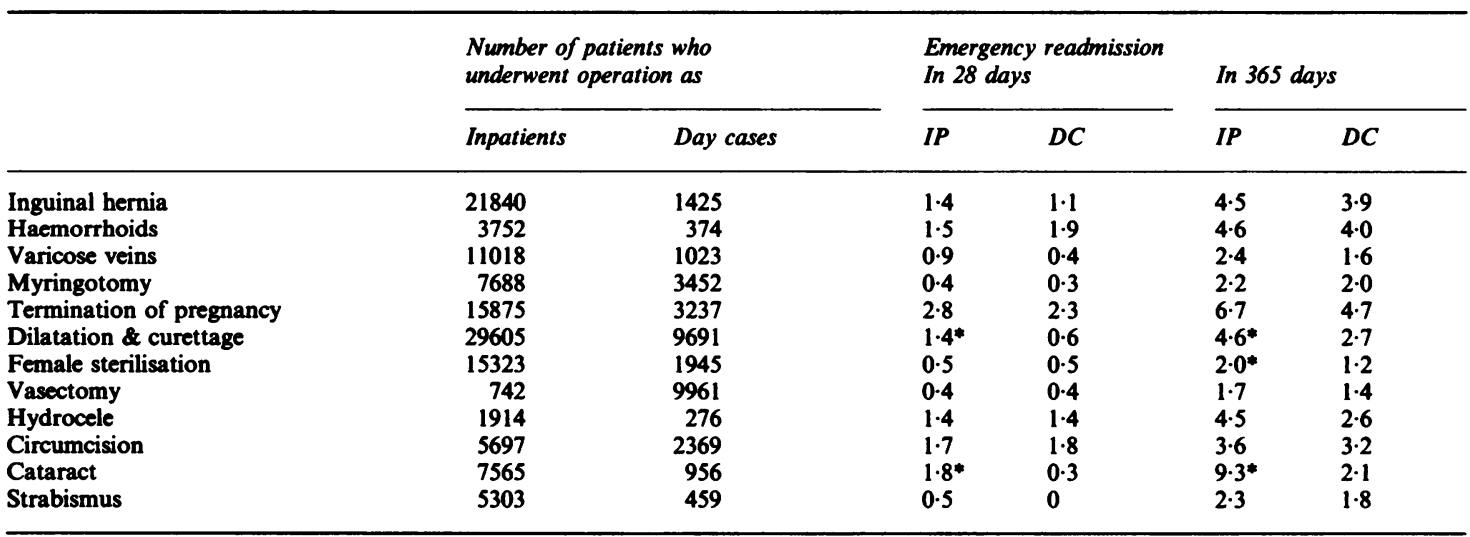

* $\chi^{2}$ values comparing readmissions following inpatient and day case care in each category significant at $p<0.05$ 
Indicators on day care. The Royal College of Surgeons has recommended, for example, that about one third of patients who undergo inguinal herniorrhaphy, and all healthy patients who undergo operations on varicose veins and haemorrhoids (except for haemorrhoidectomy), could be treated on a day case basis. Day surgery was only used for a minority of patients who underwent these operations in the five districts in this study and there appears to have been no rise in the use of day care for these conditions over the past few years.

Day surgery is particularly recommended for women requiring minor gynaecological surgery and for children. In these districts, the three gynaecological operations included in the study-termination of pregnancy, sterilisation and dilatation and curettage - were increasingly undertaken on a day case basis although the use of day case care for patients in these categories was still well under 50 per cent by 1985. The use of day case care for myringotomy increased strikingly during the period and that for circumcision increased from 25 per cent to 37 per cent.

Day surgery for cataract was increasingly undertaken in district 5 , where randomised controlled trials have demonstrated the effectiveness and acceptability of such treatment, ${ }^{10}$ but was not used elsewhere. The treatment of strabismus in day care, particularly for children, has been recommended by the Royal College of Surgeons but was only used to any extent in district 5 . High levels of day surgery were employed in the five districts for vasectomy.

Considerable variation between districts in the use of day surgery was evident. For example, there was striking variation between the five districts in operations on inguinal hernia, haemorrhoids, varicose veins, myringotomy, termination of pregnancy, dilatation and curettage, female sterilisation, operations on hydrocele and circumcision.

We considered the possibility that at least some of the variation found over time or between districts may have been attributable to artefacts of recording of data. In particular, problems of definition may arise at the boundary of what is considered to be day case treatment rather than outpatient treatment. ${ }^{11}$ Hospital Activity Analysis (HAA) records are completed for day cases; they are not completed for outpatients. A comparison between the independent counts given by the HAA and SH3 for aggregate numbers of day cases in each relevant specialty in each district in each year showed good agreement between the two sources of data. We know that for some other conditions not considered here (eg, gastroscopy in general medicine), where the distinction between a day case and an outpatient investigation may be almost arbitrary, there is a tendency to count the cases in the SH3 statistics (which is administratively easy to do) but not to include them in HAA (which involves the completion of a detailed form). It is also possible that some operations are undertaken on an outpatient basis which would therefore not be eligible for recording in HAA or SH3. Data on the recorded use of day case care for a range of conditions have recently been presented to the clinicians in surgical specialty subcommittees. From this we have feedback on whether they believe that there has been any serious underrecording of their use of day care for the conditions covered in this paper. Such discussions indicate that there may have been some underrecording of day cases for myringotomies in District 2, for dilatation and curettage in District 1, and possibly for vasectomy in several districts (where, in any case, the use of day case care is generally high). With these possible exceptions, we do not think that artefacts of recording have contributed materially to the differences found for the conditions reported here. Furthermore, as tables 2 and 3 show, the data for all conditions reported here are based on substantial numbers of cases recorded in HAA. This means at the least that, for conditions where the percentage of day cases is low, large numbers of patients with these conditions have undergone care as inpatients.

One of the main advantages of day case surgery is the lower cost per case, both in revenue and in terms of greater efficiency in the use of capital stock, compared with inpatient surgery. These economic gains may be partially offset in two ways. In the first place capital investment may be needed to create a purpose made day case unit; and secondly, the overall costs of provision of hospital care may rise if more patients are treated as a result of a higher throughput. Whether a higher throughput is an advantage or a disadvantage may depend on how hospitals are financed. If funding for hospitals is based on volume of workload, as seems increasingly likely to become the case in England, ${ }^{12}$ a greater volume of patients treated should represent a financial gain for the hospital. It also seems likely, however, that the savings in the hospital sector will be offset to some extent by increased costs outside hospital. The economic dimension to readmissions is worth noting. A higher readmission rate following day case surgery than inpatient surgery would erode the cost advantage of the former. In this study, however, readmission rates following day case and inpatient surgery were broadly similar. The economic arguments are summarised in table 5.

The reasons for continued reluctance to undertake day care for the treatment of these conditions in some districts require further consideration. Day surgery may be unpopular because surgeons believe that recovery would be adversely affected by being out of reach of immediate medical care. However, the similarities in emergency readmission rates comparing 
Table 5 Summary of economic arguments for and against the use of day case surgery

\begin{tabular}{|c|c|}
\hline Advantages & Disadvantages \\
\hline Lower costs per case: ${ }^{13}$ & $\begin{array}{l}\text { Increased overall costs if } \\
\text { increased throughput leads to the } \\
\text { treatment of more patients }\end{array}$ \\
\hline lower "hotel" revenue costs & $\begin{array}{l}\text { Capital cost of dedicated day } \\
\text { case ward }\end{array}$ \\
\hline $\begin{array}{l}\text { closing day case ward at } \\
\text { night and at weekends }\end{array}$ & $\begin{array}{l}\text { More highly trained staff, } \\
\text { generally consultants and senior } \\
\text { registrars } 6\end{array}$ \\
\hline $\begin{array}{l}\text { more efficient use of staff, } \\
\text { higher throughput }\end{array}$ & $\begin{array}{l}\text { Greater workload and strain on } \\
\text { nursing staff }\end{array}$ \\
\hline $\begin{array}{l}\text { Financial saving for hospital } \\
\text { service by transferring } \\
\text { postoperative care from } \\
\text { hospital to patient and } \\
\text { family }{ }^{3}\end{array}$ & $\begin{array}{l}\text { More visits to outpatients, GP } \\
\text { and physiotherapy, more visits } \\
\text { by district nurse }{ }^{3} \text { (will } \\
\text { vary according to the type of day } \\
\text { case procedure) }\end{array}$ \\
\hline $\begin{array}{l}\text { Lower capital costs: fewer } \\
\text { beds needed }^{3} \\
\text { Reduction of waiting list }{ }^{7}\end{array}$ & $\begin{array}{l}\text { Reduced waiting list only } \\
\text { achieved if additional, not } \\
\text { replacement, surgery }\end{array}$ \\
\hline $\begin{array}{l}\text { Day case surgery cheaper even } \\
\text { allowing for treatment failures } \\
\text { and readmissions }{ }^{14}\end{array}$ & $\begin{array}{l}\text { More treatment failures for } \\
\text { certain conditions }\end{array}$ \\
\hline
\end{tabular}

day cases and inpatients in this study go some way towards reinforcing the findings of randomised controlled trials, that there is generally no increased risk attached to day case surgery given appropriate patient selection. In some places it is possible that day case care is underutilised because the requisite facilities and administrative support services are not present. As an extreme example, day case surgical units are sometimes the target for temporary closure in times of need for districts to make financial savings. It is also probable that the enthusiasm of individual consultants for day surgery is a major factor accounting for differences between districts and for whether or not the use of day case care increases over time.

We thank Dr Monica Roche for helpful comments from the surgical specialty subcommittees. The Unit of Clinical Epidemiology is funded by the Department of Health and is part of the Department of Community Medicine and General Practice, University of Oxford.

Address for correspondence and reprints: J Henderson MSc, Unit of Clinical Epidemiology, Oxford Regional Health Authority, Old Road, Headington, Oxford OX3 7LF

\section{References}

${ }^{1}$ Farquharson EL. Early ambulation with special reference to herniorrhaphy as an outpatient procedure. Lancet 1955; i: 517-9.

${ }^{2}$ Lord PH. A day-case procedure for the cure of third-degree haemorrhoids. Br J Surg 1969; 56: 747-9.

${ }^{3}$ Russell IT, Devlin HB, Fell M, Glass NJ, Newell DJ. Daycase surgery for hernias and haemorrhoids: a clinical, social, and economic evaluation. Lancet 1977; i: 844-7.

${ }^{4}$ Ruckley CV, Cuthbertson C, Fenwick N, Prescott RJ, Garraway WM. Daycare after operations for hernia or varicose veins: a controlled trial. $B r J$ Surg 1978; 65: 456-9.

${ }^{5}$ Pineault R, Contandriopoulos AP, Valois M, Bastian ML, Lance JM. Randomized clinical trial of one-day surgery: patient satisfaction, clinical outcomes and costs. Med Care 1985; 23: 171-82.

${ }^{6}$ Royal College of Surgeons of England. Guildelines for daycase surgery. London: Royal College of Surgeons, 1985.

${ }^{7}$ Haworth EA, Balarajan R. Day surgery: does it add to or replace inpatient surgery? $\mathrm{Br}$ Med $J$ 1987; 294: 133-5.

${ }^{8}$ Oxford Regional Health Authority, 1984. Regional Strategic Plan 1984-1994.

${ }^{9}$ Department of Health and Social Security. Comparing health authorities: health service indicators 1983-86. London: DHSS, 1988: 42-3.

${ }^{10}$ Ingram RM, Banerjee D, Traynar MJ, Thompson RK. Day-case cataract surgery (abstract). Trans Ophthalmol Soc 1980; 100: 205.

${ }^{11}$ Hill A. Day cases: what are we counting? Community Med 1988; 10: $180-4$.

12 Department of Health. Working for patients. London: HMSO, 1989.

${ }^{13}$ Burn JMB. Responsible use of resources: day surgery. $\mathrm{Br}$ Med J 1983; 286: 492-3.

14 Beresford SAA, Chant ADB, Jones HO, Piachaud D, Weddell JM. Varicose veins: a comparison of surgery and infection/compression sclerotherapy. Five year followup. Lancet 1978; i: 921-4.

Accepted for publication April 1989 